NEWS

\title{
Mitochondria: An energy explanation for autism
}

\author{
BY LAURA DATTARO
}

22 NOVEMBER 2021

Almost every human cell teems with a potpourri of tiny powerhouses: mitochondria. Up to thousands of them. These organelles use oxygen to convert the nutrients from the food you eat into a form of energy the body can use. The brain consumes a lot of this energy - about 20 percent. Could changes in mitochondria, then, affect how the brain functions and contribute to autism? Read the related article, Meet the 'mitomaniacs' who say mitochondria matter in autism.

Cite this article: https://doi.org/10.53053/EKOQ3250 